\title{
IT Employees Training Methods and Job Performance - An Empirical Investigation
}

\author{
Mr. Ramesh D \\ Research Scholar, Bharathiar University, Coimbatore. \\ Email id: ramesh.may1981@gmail.com
}

Dr. N. Mohan

Principal, Sadhguru Sainath Degree College, Kudlu, Bangalore.

Email id: mcnmohan@gmail.com

\begin{abstract}
With the growing body of research in the field of human resource functions this study intends to find the impact of employee's training methods towards their job performance. The data were gathered from 576 employees working in IT companies at Bangalore. The middle level employees were chosen as the samples. The PLS based approach is used to test the proposed hypotheses. The training methods is categorized in two forms as On-the Job training (OJT) and specialized training and its influence towards the job performance is assessed. Based the research framework formulated the findings of the study claimed that both the training methods showed a positive influence towards the employee's job performance. Specifically, the specialize training shows greater impact on performance of the employees than that of other training methods. Further the study also suggests managerial implications by helping the management in realizing the importance of specialized training and makes them to formulate plans in identifying the training methods that suits to the individual employee capabilities.
\end{abstract}

Keywords: Employees Training Method, Job Performance, Employee Engagement, IT Employee

\section{Introduction}

Employees' attitudes and behavior are changed as a result of the training process, which is informative. Additionally, it helps in their efficiency. Learning new skills and expanding on previously acquired knowledge are the primary goals of training, which helps employees do their jobs more effectively. In the other direction, employee development and training improves their self-confidence and ability to deal with work-related stress, both of which lead to an increase in the level of employee commitment.

Training as a concept has become a difficult decision for the company to make in the present day because of aspects such as cost and time. Because employee training is a sort of continual learning that results in a change in behavior, the firm has to spend more money and time on educating new employees. It is possible for an organization to reap the benefits of training and 
development by increasing the degree of involvement of its employees. Employee engagement and job performance improve as a result of providing high-quality training.

The current study focuses on Information Technology (IT) and IT enabled services (ITES) in Bangalore's service sector. Bangalore, widely known as "India's Silicon Valley", has recently emerged as a major hub for IT and ITeS enterprises. Bangalore's economy accounts for $87 \%$ of the state's GDP and $98 \%$ of software exports.

\section{Literature Review}

Timsal et al. (2016) investigated the effectiveness of job training. Job training inspires people, builds dedication, and develops skills. The surveys were distributed among selected employees of McDonald's and Domino's Pizza in the UK. The inquiries focused on the employee's training needs and their work reliability. The training program is very rigorous and planned. The training program is totally centered on the company's and employee's needs. The training program must also be employee-friendly.

Anitha and Kumar (2016) found that employees play a vital part in the organization's performance. An employee's abilities, knowledge, competence, and reliability are critical to the organization's progress. Employees must be trained constantly to improve their experiences, skills, and performance. Employee performance growth is determined by employee selection, education, and experience. The remaining 50\% of employee involvement is based on motivation, rewards, incentives, job satisfaction, environmental conditions, supervision, etc. The Human Resource staff ensures proper training delivery and employee satisfaction.

According to Jiang et al. (2016), inadequate human capital training can destroy experts. On the other hand, it may cause employment loss and work turnover. The temporary specialist should be given great space occupation and importance. Employed in small businesses, employees with limited mobility and less skilled in the principal work should be given special attention. More volunteers and finances for hands-on training for small businesses and the unemployed are needed. Aside from the prepared specialist, consider the work labors. Finally, it shows that the rights of guarantee and labor should be regarded equally, especially in metropolitan areas.

Roshchin and Travkin (2017) studied the impact of on-the-job training on several new businesses. The study is based on modern technologies and training intensity. The questionnaires were raised among 2000 Russian companies, and the profit statistics were measured. The company's profit is governed by aspects like manufacturing technology, business activity, and innovation. The training should be consistent in terms of frequency, intensity, number, and harshness. The product market games produce a poor picture of training and development that must be addressed. Productivity will be hampered due to staff ignorance. Thus, workers need to be trained to improve their skills and enhance firm profitability. 
Lee (2017) evaluated the military's commitment to their work in Korea. It improves their confidence and execution power of military staffs. The SPSS study involves 220 military volunteers. The program has two types. 1. Activity-based and 2. Exam-based programs The activity-based program collects data every 3-4 hours on absorption capacity, off-the-job capacity, occupation, and stamping improvement. The exam-based program develops their knowledge of advanced technology and preparing spirit. Third, to adjust to new environments and recognize the distinction between learning society and learning intensity. Fourth, dynamic measurement of dedication to duty with intellectual and hierarchical execution.

Meshckeriakova and Vermeulen (2017) investigated the impact of disinterested workers on work output. This research calculates the profit of their educational monuments. The production aim is harmed when staff work invisibly. To reach the organization's current aim, it is critical to focus on low-talent individuals. Studies show that low level training, explicit relationships, job change activity, and commencing over strengthening can enhance labor efficiency. Predicts market situation, employee talent enhancement and proficiency benchmark.

Nashar et al. (2018) demonstrated the impact of training and development on employee job satisfaction. The test is given to workers of PT Garuda Indonesia Training Centre. The questionnaires are based on a survey of only fifty employees. The study employs the Structural Equation Model Method using Smart PLS Investigation Instrument 3.0. The study and results reveal a massive and favorable relationship between fulfillment $(\mathrm{H} 1)$ and $(\mathrm{H} 2)$. In this way, personnel at the PT Garuda Indonesia Training Centre achieve employment satisfaction and fulfillment.

Giga et al. (2018) studied the systematic approach for boosting organizational efficiency. The employee's knowledge, skills, talents, potential, capabilities, and expertise are factors that improve efficiency. Communication between training and job retention creates a good relationship. Continual training controls staff departures. According to the American Society of Training Development, employees should be trained step by step to fulfill the organization's aim. The training increases staff commitment to the job.

According to Sambrani (2018), the major goal of on-the-job training is to please the employee. The questions are raised among 80 employees of an IT firm in Hyderabad. The data is collected on three key factors: distribution, interpretation, and acquisition. The Likert Five-point scale is used to collect data from employees. Regression analysis, mode, standard deviation, percentages, and mean difference verify the data. Employees are more satisfied with their jobs if they have a good working relationship and are flexible with their work schedule.

Jaworski et al. (2018) investigated the benefits of hospital employee training. Job training improves job happiness, guest satisfaction, and reduces business costs. Most organizations do not spend in training part-time personnel. But they invest in temporary labor to reach their aims quickly by teaching them current ways. It also shows a link between pay and staff training. Moreover, current research shows that training is done to develop abilities and encourage 
employees, not to increase remuneration. The surveys are sent to 348 supervisors in Chinese manufacturing firms. It enhances abilities, performance, knowledge, and quickly. Training is vital in task planning, organizational behavior, and work improvement. Thus, the human resource team should prioritize employee training.

Bibi, Ahmad, and Majid (2018) show that training and development programs assist recruit new employees and retain existing employees. Previous research shows a negative correlation between staff retention and training. Appreciation and recognition at work can increase employee loyalty. Training is one of the key methods to increase an employee's abilities, knowledge, and competence. The questions are raised by 150 Research Facilitation Unit respondents. The quantitative data is represented using a Likert scale. Finally, work satisfaction and staff retention help achieve organizational goals.

Shirsavar et al. (2018) studied the Iran Forensic Medicine Organization's personnel training (IFMO). The Forensic Medicine Organization provides both model and test based training (OJT). In 2017, the Iran Forensic Medicine Organization surveyed 2300 personnel, of whom 338 were chosen for multi-stage categorization based on Cochran's Formula around 15 regions. Cronbach's Alpha Coefficient Method (values $=0.89$ and 0.87). It uses recurrence, mean, correlation coefficient, standard deviation, and SEM to collect and file data. The improvements in performance include authoritative, work, and exact execution. In the OJT-based model, you can record points, assessments and usage. The OJT approach is one way to increase employee performance.

Sareen (2018) investigated the impact of training on job satisfaction. Job satisfaction determines an employee's willingness, commitment, satisfaction, and positive. Job happiness is critical to the organization's success. So the Human Resource Development team has added new factors to boost employee satisfaction. The organization's main issue is retaining employees. The study clearly reveals the link between training and development, work happiness, and employee performance.

Guan and Frenkel (2019) investigated the effects of training on semi-skilled workers in manufacturing. Manufacturing companies' output is heavily reliant on human resources. There is a link between on-the-job and training-based performance. The sample includes 348 supervisors from a Chinese manufacturing firm. The employee's task fulfillment, work engagement, and organizational behavior determine the HR Management Team's strength. Contextual factors influence the training-based connection inside an organization. The HR team should focus on the employee's perspective on the training and learning program. Training and education are based on ability, performance, motivating and providing opportunity.

Nguyen and Shao (2019) researched on-the-job and off-the-job training for employees. Particularly, training is dependent on environmental factors, gender factors, and work characteristics. The questionnaire was given to 221 female employees in the Vietnam office. The survey found that most women choose Off-Job-Training using GNs technique. Finally, both off-the-job and on-the-job training affect turnover intention. It also teaches us about the 
female employees' patience and dedication to their jobs in Southeast Asian countries, their participation in social activities, and their organizational behavior.

Kumar et al. (2019) explore technical employee training in Biotech. Employees should be trained to achieve a certain level of performance. On-the- Job training is based on five factors: practical, hypothetical, skill development, personal acquaintances, and work performances. It teaches the employee how to attain the organization's purpose. Work stress and rotational work impair performance. To fulfill the company's goal, it is critical to boost staff morale. Thus, job satisfaction, appropriate working conditions, training, promotion, and rewards can improve employee performance.

\section{Research Questions}

It is always a challenging task for any organization to make the employees to give their potential performance in the work. One of the solutions that the firms have identified is providing the training for the employees for better job performance. In order to examine this, the subsequent questions is as follows

1. How the two forms of training (On the Job training and Specialized training) contribute towards increase in employees job performance?

\subsection{Research Objectives}

The major objective of this study is to understand the influence of on-job training and specialized training over job performance of IT employees.

1. To examine the influence of on-the job training towards employee's job performance

2. To examine the influence of specialized training towards employee's job performance

\subsection{Research Hypothesis}

H1: On-the job training has positive influence on employee's job performance

H2: Specialized training has positive influence on employee's job performance

\subsection{Research Methodology}

Sampling Design: The primary data for the study was collected through the well-structured questionnaire. The questionnaire consists of two sections. The first session was based on the demographic profile of the respondents, which includes questions like the respondents age, years of experience, area of living, and other personal characteristics. The second part of the questionnaire consists of items adopted from the existing literature. The second part of the instrument was measured using five-point Likert scale, where 5 indicated 'strongly agree' to 1 being 'strongly disagree'. The questionnaire was distributed to the respondents through online and offline mode. Few questionnaires were given in-person to the IT employees in the middle level of management hierarchy and few who did not had time to fill on the spot were sent through Google forms.

Overall, 900 questionnaires were circulated to the target audience (IT employees) and out of which 574 responded to the study instrument. Out of the 574 received responses, 48 
questionnaires were rejected as there were too many missing data. From the overall 574 responses, 526 valid responses are considered for the study. This indicates about 58.4 percent response of the participants.

3.3.1 Measures: To measure the "on-the job training" the items were adopted from Okereke and Nnenna (2011) and work Aroge (2012) with nine items. To determine the "specialized training", the items were deliberated from work of Aroge (2011) with six items. Finally "job performance" is measured with nine items adopted from IWPQ - Individual work performance questionnaire by Koopmans et al (2011).

\section{Data Analysis and Results}

In order to test the proposed hypotheses of the study the data analysis was performed using SPSS and Smart PLS. The preliminary test on tests on reliability and validity of the scales were also established. The demographic details represented in percentage analysis is depicted in the Table 1 below.

The demographic profile of the respondents which includes various personal characteristics of the respondents like gender, age, education, family type, experience, and area of living. It is seen that, out of 526 respondents, 51.9 percent are males and 48.1 percent are females. Looking into the age of the respondents, most of the respondents falls between the age of greater than 28 to 26 , followed by greater than 36 to 48 being 21.3 percent, and 19.4 percent falls between 20 and 28, and finally 18.2 percent falls above 46. On the classification of education, none of the respondents have told that they are school level, 169 have mentioned that they have gone undergraduate ( 24.5 percent), 298 have done their post graduate (56.7 percent) and 59 have done other courses like diploma, and doctorate of philosophy (18.8 percent).

Looking into the family type, 260 of the respondents stays in a nuclear family (49.4 percent) and 50.6 percent of the respondents stays in the joint family (266 respondents). Experience of the respondents shows that, 114 (21.7 percent) are having less than a year of experience, 134 (25.5 percent) are having an experience of one year to three years. The area of living of the respondents shows that 107 respondents (20.3 percent) are from rural area, 318 (60.5 percent) respondents are from urban area and 101 respondents (19.2 respondents) are from sub-urban area.

Table 1: Demographical analysis

\begin{tabular}{|l|l|l|l|}
\hline \multicolumn{2}{|c|}{ Demographic variables } & No.of. respondents & Percentage \\
\hline \multirow{3}{*}{ Gender } & Male & 273 & 51.9 \\
\cline { 2 - 4 } & Female & 253 & 48.1 \\
\hline \multirow{4}{*}{ Age } & $20-28$ & 102 & 19.4 \\
\cline { 2 - 4 } & $>28-36$ & 216 & 41.1 \\
\cline { 2 - 4 } & $>36-46$ & 112 & 21.3 \\
\cline { 2 - 4 } & Above 46 & 96 & 18.2 \\
\hline
\end{tabular}




\begin{tabular}{|l|l|l|l|}
\hline \multirow{5}{*}{ Education } & School level & 0 & 0 \\
\cline { 2 - 4 } & UG & 169 & 24.5 \\
\cline { 2 - 4 } & PG & 298 & 56.7 \\
\cline { 2 - 4 } & Others & 59 & 18.8 \\
\hline \multirow{5}{*}{ Experience } & Nuclear & 260 & 49.4 \\
\cline { 2 - 4 } & Joint & 266 & 50.6 \\
\hline \multirow{3}{*}{ Area of living type } & Less than a year & 114 & 21.7 \\
\cline { 2 - 4 } & 1 year -3 years & 134 & 25.5 \\
\cline { 2 - 4 } & 3 years 1 month -5 & 196 & 37.3 \\
\hline & years & & \\
\cline { 2 - 4 } & More than 5 years & 82 & 15.6 \\
\hline & Rural & 107 & 20.3 \\
\cline { 2 - 4 } & Urban & 318 & 60.5 \\
\cline { 2 - 4 } & Sub-urban & 101 & \\
\hline
\end{tabular}

Followed by the demographic representation, the Table 2, depicts the correlation for the study variables (dependent variables, independent variables, and mediating variables). To measure the job performance, the study has used on-the job training and specialized training that influences job performance. Both the constructs like on-the job training and specialized training shows positive association towards job performance. Further, the correlation coefficient " $r$ " lies between the range of 0.300 and 0.800 which signifies the substantial positive linear relationship for the study variables. The outcome of the correlation coefficient acts as a primary support for the proposed hypotheses of the study.

Table 2: Descriptive, Inter correlation and Square root of AVE

\begin{tabular}{|l|l|l|l|l|l|l|l|}
\hline S.No & Constructs & Mean & SD & 1 & 2 & 3 & 4 \\
\hline 1 & On-the Job training & 3.63 & 0.64 & 0.531 & & & \\
\hline 2 & Specialized training & 3.76 & 0.68 & $0.52^{* *}$ & 0.229 & & \\
\hline 3 & Job performance & 3.54 & 0.63 & $0.35^{* *}$ & $0.30^{* *}$ & 0.513 & \\
\hline
\end{tabular}

Notes: Diagonal line placed in italic style show the square root of the AVE of each construct. **Significant at 0.01 level (two-tailed)

Along with the preliminary tests which was carried to establish the reliability and validity of the adopted scales used for the study variable, the confirmatory factor analyses were also performed in order to fulfill the fundamental criteria set for structural equation modelling (Hair et al., 2013). Thus initially with the acceptance of normality, the confirmatory factor analyses was performed and the factor loadings were extracted. The CFA result claimed KMO (0.946, $\mathrm{p}<0.000)$ value greater than threshold value of 0.8 indicates the sample adequacy for the proposed model. Also the factor loadings of all respective factors were found to be higher value of above 0.60 which indicates the validity confirmation for the scales used. With respect to the reliability the various forms of reliability includes Cronbach's alpha, Average variance extracted (AVE), Composite reliability (CR) were examined and results are in line with the 
expected criteria as it showed $\alpha>0.84, \mathrm{AVE}>0.80$ and $\mathrm{CR}>0.7$. Henceforth the validity and reliability of the study model is established which is depicted in the Table,2.

Table 2: Factor loadings (CFA), Reliability and Validity measures

\begin{tabular}{|c|c|c|c|c|}
\hline Items & $\begin{array}{l}\text { Cronbach's } \\
\text { Alpha }\end{array}$ & $\begin{array}{l}\text { Factor } \\
\text { Loadings }\end{array}$ & CCR & AVE \\
\hline \multicolumn{5}{|c|}{ On-the Job Training } \\
\hline OJT1 & \multirow[t]{9}{*}{0.950} & .597 & \multirow[t]{9}{*}{0.934} & \multirow[t]{9}{*}{0.823} \\
\hline OJT2 & & 693 & & \\
\hline OJT3 & & .669 & & \\
\hline OJT4 & & .662 & & \\
\hline OJT5 & & .679 & & \\
\hline OJT6 & & .681 & & \\
\hline OJT7 & & .642 & & \\
\hline OJT8 & & .470 & & \\
\hline OJT9 & & .474 & & \\
\hline \multicolumn{5}{|c|}{ Specialized Training } \\
\hline SP1 & \multirow[t]{6}{*}{0.897} & .529 & \multirow[t]{6}{*}{0.881} & \multirow[t]{6}{*}{0.865} \\
\hline $\mathrm{SP} 2$ & & .450 & & \\
\hline SP3 & & .824 & & \\
\hline SP4 & & .861 & & \\
\hline SP5 & & .891 & & \\
\hline SP6 & & .875 & & \\
\hline \multicolumn{5}{|c|}{ Job Performance } \\
\hline JP1 & \multirow[t]{2}{*}{0.889} & .700 & \multirow[t]{2}{*}{0.868} & \multirow[t]{2}{*}{0.703} \\
\hline JP2 & & .817 & & \\
\hline
\end{tabular}




\begin{tabular}{|c|c|}
\hline JP3 & .797 \\
\hline JP4 & .791 \\
\hline JP5 & .774 \\
\hline JP6 & .800 \\
\hline JP7 & .823 \\
\hline JP8 & .635 \\
\hline JP9 & .769 \\
\hline
\end{tabular}

\subsection{Measurement model}

Followed by the CFA, the model fit of the proposed model were analyzed in order to obtain the universal goodness of fit. The criteria for the model fit were thus established and validated using AMOS measure model. The findings highlighted the goodness as suggested by Hair et al. (2013), with the following indices includes $\chi 2(\mathrm{CMIN} / \mathrm{df})=2.48$, $\mathrm{p}$-value $=0.001$, GFI $=0.90$, $\mathrm{AGFI}=0.87, \mathrm{CFI}=0.94, \mathrm{NFI}=0.89, \mathrm{IFI}=0.94, \mathrm{TLI}=0.89, \mathrm{RMSEA}=0.07$.

\subsection{Structural Model}

With the acceptance of model fit, the path relationship of the study variables was established further through structural equation modeling. The path estimates according to observed and criterion variable of the study, On-the job training, Specialized training and job performance. The findings of path co-efficient were given in Table 4, as it also claimed acceptance of the proposed hypotheses and thus supports $\mathrm{H} 1$ and $\mathrm{H} 2$. First, the on-the job training showed significant positive relationship with job performance $(\beta=3.517, \mathrm{p}<0.000)$ and further the specialized training also showed positive relationship with job performance as well $(\beta=7.618$, $\mathrm{p}<0.000)$. Thus, the $\mathrm{H} 1$ and $\mathrm{H} 2$ hypotheses with respect to job performance is confirmed.

Table 3: Hypothesis Testing

\begin{tabular}{|l|l|l|l|l|l|}
\hline Hypothesis & Relationship & Std. Estimates & CR (t-value) & p-value & Decision \\
\hline $\mathrm{H} 1$ & OJT $\rightarrow \mathrm{JP}$ & 0.086 & 3.517 & 0.000 & Accepted \\
\hline $\mathrm{H} 2$ & SP1.Tr $\rightarrow \mathrm{JP}$ & 0.051 & 7.618 & 0.000 & Accepted \\
\hline
\end{tabular}

Notes: OJT- On-the Job training, SPL.Tr- Specialized Training, JP- Job Performance $* * p<0.01$ 


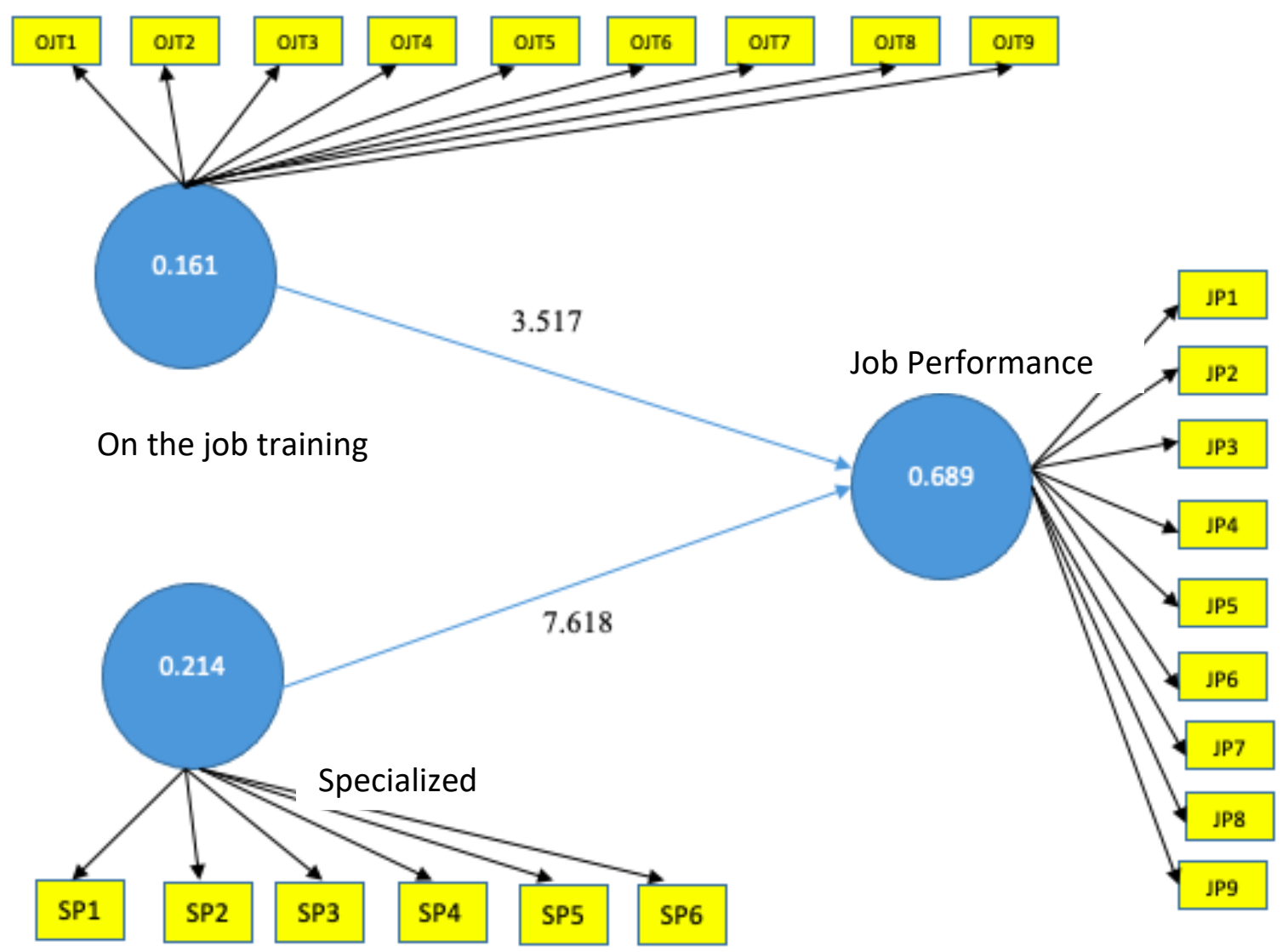

\subsection{Result and Discussion}

The results were highlighted in Table 3, which shows the direct, indirect effect and path analysis that has shown the positive association among the variables at the significance level of 0.05 (95 percent confidence level). The t-statistics is also greater than the recommended value of 1.96. Looking into the individual hypotheses, the following outcomes are attained.

\section{H1: On-the job training has positive influence on employee's job performance}

The path co-efficient between on-the job training and job performance showed positive significant relationship, $(\mathrm{t}=3.517, \mathrm{p} \leq 0.001)$ which means that the training has positive influence towards the job performance. This positive effect is supported by previous researches as well ( Farooq and Aslam, 2011; swart et al, 2005; Aqel, 2020).

\section{H2: Specialized training has positive influence on employee's job performance}

The path co-efficient between specialized training and job performance showed positive significant relationship $(t=7.618, p \leq 0.001)$ which means that the training which is exclusively given to specific employees has positive influence towards their job performance. This positive effect is supported by previous researches as well ( Farooq and Aslam, 2011; swart et al, 2005; Aqel, 2020). 


\section{Conclusion}

From the research study carried, it is evident that an employee in the organisation plays a major role for efficient attainment of organisational goal by performing well in their specified job. Though a decades ago it is perceived that training has no emotional connect with the employees, eventually it was proven wrong. The result of this study also clearly depict the importance of training and development practices on employees personal outcomes such as job performance. Particularly, the result highlights the difference of result based on training methods used to examine the employee outcomes. Compared to On-the Job training method the specialized training predicts employee engagement and thereby greater job performance. The specialized training such as individualized trainings on specific skills, workshops on new systems or applications, research opportunities on the enhancing skills required to deal with new challenges helps the employees to gain more confidence in doing the right things in job.

\section{Limitation and Future direction}

The research study has its own limitations. The following are the points can be considered as its limitation but which can give room for further research to be carried. The major limitation of the study can be viewed from the point of the sampling area. The study focused on the employees working in IT sectors of only one city in Karnataka. But the limitation of the present study can justify it in a way that the city chosen for the study is a place referred as IT hub where all the top IT players are present and thus the there is a scope to attain the objectives of the study. Though the further can also be attempted in future by considering more of the places to validate the model to the next level.

\section{References:}

1 Anitha, R., \& Kumar, M. A. (2016). A study on the impact of training on employee performance in private insurance sector, Coimbatore district. International Journal of Management Research and Reviews, 6(8), 1079.

2 Aroge, S. (2011, November). Productivity Improvement and Corporate Survival: Challenges to Trade. International Journal of Business Administration, 2(4), 136.

3 Aroge, S. T. (2012): Employee's Training and Development for Optimum Productivity:The Role of Industrial Training Fund (ITF), Nigeria, Developing Country Studies, 2(4), 50-59.

4 Bibi, P., Ahmad, A., \& Majid, A. H. A. (2018). The impact of training and development and supervisor support on employees retention in academic institutions: The moderating role of work environment. Gadjah Mada International Journal of Business, 20(1), 113-131.

5 Giga, S. I., Fletcher, I. J., Sgourakis, G., Mulvaney, C. A., \& Vrkljan, B. H. (2018). Organisational level interventions for reducing occupational stress in healthcare workers. The Cochrane Database of Systematic Reviews, 2018(4).

6 Guan, X., \& Frenkel, S. J. (2019). Explaining supervisor-subordinate guanxi and subordinate performance through a conservation of resources lens. human relations, 72(11), 1752-1775.

7 Jaworski, C., Ravichandran, S., Karpinski, A. C., \& Singh, S. (2018). The effects of training satisfaction, employee benefits, and incentives on part-time employees' commitment. International Journal of Hospitality Management, 74, 1-12. 
8 Koopmans, L., Bernaards, C. M., Hildebrandt, V. H., Schaufeli, W. B., de Vet Henrica, C. W., $\&$ van der Beek, A. J. (2011). Conceptual frameworks of individual work performance. Journal of Occupational and Environmental Medicine, 53, 856-866.

9 Lee, D. (2017). How to Improve the ROK and US Military Alliance Against North Korea's Threats to Cyberspace: Lessons From NATO's Defense Cooperation. Naval Postgraduate School Monterey United States.

10 Meshcheriakova, O., \& Vermeulen, S. (2017). On-the-job-training as a signal: Why loweducated workers invest less in further training (No. 021).

11 Mohammadi, Z., Rezghi Shirsavar, H., Ziaeiy, M. S., \& Hashemnia, S. (2018). Designing an On-the Job-Training Model and examining it to Promote and Improve Staff's Performance. Biannual Journal of Education Experiences, 1(1), 27-40.

12 Nashar, M., Parashakti, R. D., \& Fauziah, H. S. (2018). Effect of Training and Job Performance on Job Satisfaction in PT Garuda Indonesia Training Center. Management Studies, 6(4), 275285.

13 Nguyen, L. T., \& Shao, Y. (2019). The impact of training on turnover intention: the role of growth need strength among Vietnamese female employees. The South East Asian Journal of Management.

14 Okereke CI, Nnenna IB (2011). Training, Manpower Development and Job Performance: Perception and Relevance among Civil Servants in Ebonyi State. Nigeria Journal of Economics and International finance 3(6):399-406.

15 Roshchin, S., \& Travkin, P. (2017). Determinants of on-the-job training in enterprises: the Russian case. European Journal of Training and Development.

16 Sambrani, S.(2018). THE IMPACT OF ON-THE-JOB LEARNING ON JOB SATISFACTION.

17 Sareen, D. (2018). Relationship between strategic human resource management and job satisfaction. International Journal of Current Research in Life Sciences, 7(03), 1229-1233.

18 Timsal, A., Awais, M., \& Shoaib, O. (2016). On job training and its effectiveness: An employee perspective. South Asian Journal of Banking and Social Sciences, 2(1), 1-22. 